\title{
Behavior in different storage conditions of Romanian tomato hybrid 'Siriana' grafted on different rootstocks
}

\author{
M. Doltu1*, E.C. Dragomir and V. Tănasă ${ }^{1}$
}

Research and Development Institute for Processing and Marketing of Horticultural Products - HORTING, Bucharest, Romania.

*Corresponding author: doltumadalina@yahoo.com

\section{ABSTRACT}

Vegetable growers from Romania obtain the average tomato productions from grafted crops are with $\mathbf{2 5 - 5 0 \%}$ higher compared to the productions from non-grafted crops. The grafted tomato production must be managed through a profitable capitalization in a fresh state on the local market. Post-harvest temperature and other factors influence the lifespan and quality of tomato fruit. Some researches were carried out on the influence of certain storage conditions on grafted solano-fruit vegetables (eggplant, tomato) in the Horting Institute. The objective of this research has been to establish the influence of rootstock on the behavior in different storage conditions of grafted hybrid 'Siriana' obtained in the year 2017 in a Venlo glasscovered greenhouse. The biological material was composed of cultivars of Lycopersicon genus: a scion, 'Siriana F1' hybrid and two rootstocks, 'Buzău' (Romanian selection) and 'Emperador F1' (interspecific Dutch hybrid). The tomatoes have been deposited for $\mathbf{2 0}$ days in bulk in plastic crates and stored in hemibiosis (temperature to $25^{\circ} \mathrm{C}$ ) and physioanabiosis (temperature to $7^{\circ} \mathrm{C}$ and relative humidity to $60 \%$ ) conditions. The rootstocks have influenced the total losses recorded on tomatoes during storage, did not significantly influence the quality of the fruit, influenced positively the firmness of the tomatoes but do not influence the firmness during the storage period under research conditions. The results obtained require the continuation, respectively the extension of the researches and on other grafted vegetable species and other storage conditions.

Keywords: grafting, hemibiosis, physioanabiosis, Romanian tomato, storage.

\section{INTRODUCTION}

Tomatoes are important vegetables in Romania, they rank the second place, after cabbage, in terms of cultivated surface and total production and the second place, after cucumbers, in crops from protected spaces (greenhouses and solariums) (www.madr.ro).

Their nutritional value consists mainly in the content of mineral substances in proportion of $0.61 \%$ (K 226-310 mg, P 24-39 mg, Mg 11-20 mg, Ca 9-15 mg/100 g) and in various vitamins (C 18-26 mg, B complex $0.5 \mathrm{mg}, \beta$ carotene equivalent $0.6 \mathrm{mg}$, PP $0.5 \mathrm{mg}$, E $0.5-1$ $\mathrm{mg}, \mathrm{K} 0.6 \mathrm{mg})$; the acidity is pleasant and stable $(0.5 \mathrm{~g} \%$ in citric acid), they have glucose 0.6 $0.7 \%$ and fiber $1.2 \%$, the inedible part of $3 \%$ and the reduced energy value, $190 \mathrm{Kcal} / \mathrm{kg}$ (Beceanu and Chira, 2003).

The tomato sector grown in protected spaces (greenhouses and solariums) is growing because modern cultivation technologies and a superior biological material (cultivars and hybrids) in terms of quantity and quality have been introduced, very genetically varied in 
shape, size, color and taste, resistance or tolerance to biotic and abiotic factors in the production biotope. Vegetable growers obtain important vegetable productions outside the natural periods and the average tomato productions obtained from grafted crops are 25$50 \%$ higher compared to the productions from non-grafted crops.

In order to obtain the best possible financial result, the superior production of grafted tomatoes must be managed through a profitable capitalization in fresh condition on the local market. Optimal storage of fresh tomatoes allows them to be marketed when the offer is small and the price is high on the market. The storage of tomatoes is practiced both during the vegetation period of the plants, but more frequently at the end of the season, when the staggering of sales contributes to maintaining the price and even to its increase. Chaux and Foury, (1994) show that tomatoes from the greenhouse are harvested at an earlier stage and must be transported from this space as soon as possible.

Temperature is the most important post-harvest factor that influences the lifespan of tomatoes. During storage, diseases and physiological disturbances are caused by cooling, respectively by inadequate temperature and exposure time; there are pathogenic fungi that cause black spots on solanaceous or alternariosis (Alternaria porii f. sp. solani) and anthracnose (Colletotrichum coccodes).

Currently, the infrastructure for sorting, calibrating and packaging of tomatoes is almost non-existent in Romania; small local producers carry out these works manually, of inferior quality and improper storage to the requirements of species, that leading to the deterioration and loss of important quantities of the production destined for fresh consumption. At the Research - Development Institute for Industrialization and Marketing of Horticultural Products - Horting Bucharest, researches were carried out on the influence of certain storage conditions on grafted solano-fruit vegetables (eggplant, tomato). Research continues concerning the storage of vegetables from grafted crops established in protected spaces (greenhouses and solariums) and/or open fields. The specific objective of this research was to establish the influence of an important technological factor, the rootstock, on the behavior in different storage conditions of the grafted Romanian tomato production obtained in the greenhouse.

\section{MATERIALS AND METHODS}

The research was done in the 2017 year at the Horting Research - Development Institute.

The biological material was made of cultivars that belong to Lycopersicon genus. This research was carried out on tomato fruits from the experimental fields established with grafted and non-grafted plants of 'Siriana' Romanian tomatoes.

'Siriana' tomatoes were grafted on two rootstocks, 'Buzău' and 'Emperador'.

The 'Siriana' tomatoes and the 'Buzău' rootstock are Romanian biological creations, obtained by researchers from SCDL Buzău. The 'Emperador' rootstock is an F1 hybrid produced by Rijk Zwaan Dutch Company and used for grafting tomatoes.

The experimental lots with grafted and non-grafted plants were established in a Venlo greenhouse on May 8, 2017, at the density of 27000 non-grafted plants/ha and 18000 grafted plants/ha, in variants grouped in line such complete blocks (randomized blocks), the Latin rectangle method and maintained according to the classic technology of tomato production. The tomato fruits used in the research were harvested from mid-July to the end of August (14, 18 July - 28 August 2017). The color was used as an indicator of the ripening phase of the fruit. They were harvested without the peduncle and stored in the third maturation phase (F3), to $90 \%$ red pigmentation. The fruits were sorted (Extra and a-I-a quality categories) and calibrated (minimum caliber of $35 \mathrm{~mm}$ ). Post-harvest treatments were not performed before storage. 
The packaging has been made manually, with a quality tolerance of $5 \%$ from weight, in plastic crates with a net weight of $5 \mathrm{~kg}$, non-arrangement of fruits (in bulk), but with a flat and uniform surface.

The storage of the crates has been made non-palletized, in a compact system, for 20 days, at an ambient temperature of $25^{\circ} \mathrm{C}$ (hemibiosis) and cold, by refrigeration at $7{ }^{\circ} \mathrm{C}$ and relative humidity of $60 \%$ (physioanabiosis).

A bifactorial experience has been organized, with 6 variants (V1, V2... - V6), of 3 repetitions each (R1, R2 and R3)/variant (Table 1). The experimental factors were:

- A factor - scion x rootstock combination:

$\mathrm{a}_{1}$ - non-grafted 'Siriana' (control);

$\mathrm{a}_{2}$ - 'Siriana' x 'Emperador';

$\mathrm{a}_{3}$ - 'Siriana' x 'Buzău'.

- B factor - storage conditions:

$\mathrm{b}_{1}$ - hemibiosis, ambient temperature $\left(\mathrm{T}^{\circ} \mathrm{C}=25\right)$;

$\mathrm{b}_{2}$ - physioanabiosis, frig $\left(\mathrm{T}^{\circ} \mathrm{C}=7, \mathrm{RU} \%=60\right)$.

Table 1. Organization way of experimental variants with tomatoes

\begin{tabular}{|c|c|c|c|}
\hline Variant & Combination & \multicolumn{2}{|c|}{ Storage conditions } \\
\cline { 3 - 4 } & scion x rootstock & Storage & Packing \\
\hline V1 $\mathrm{a}_{1} \mathrm{~b}_{1}$ & 'Siriana' (Control) & Hemibiosis & plastic crate, bulk \\
\hline V2 $\mathrm{a}_{1} \mathrm{~b}_{2}$ & -idem- & Physioanabiosis & -idem- \\
\hline V3 $\mathrm{a}_{2} \mathrm{~b}_{1}$ & 'Siriana' x 'Emperador' & Hemibiosis & -idem- \\
\hline V4 $\mathrm{a}_{2} \mathrm{~b}_{2}$ & -idem- & Physioanabiosis & -idem- \\
\hline V5 $\mathrm{a}_{3} \mathrm{~b}_{1}$ & 'Siriana' x 'Buzău' & Hemibiosis & -idem- \\
\hline V6 $\mathrm{a}_{3} \mathrm{~b}_{2}$ & -idem- & Physioanabiosis & -idem- \\
\hline
\end{tabular}

Figure 1 describes the aspect of tomatoes harvested in F3 and introduced in-experiment.

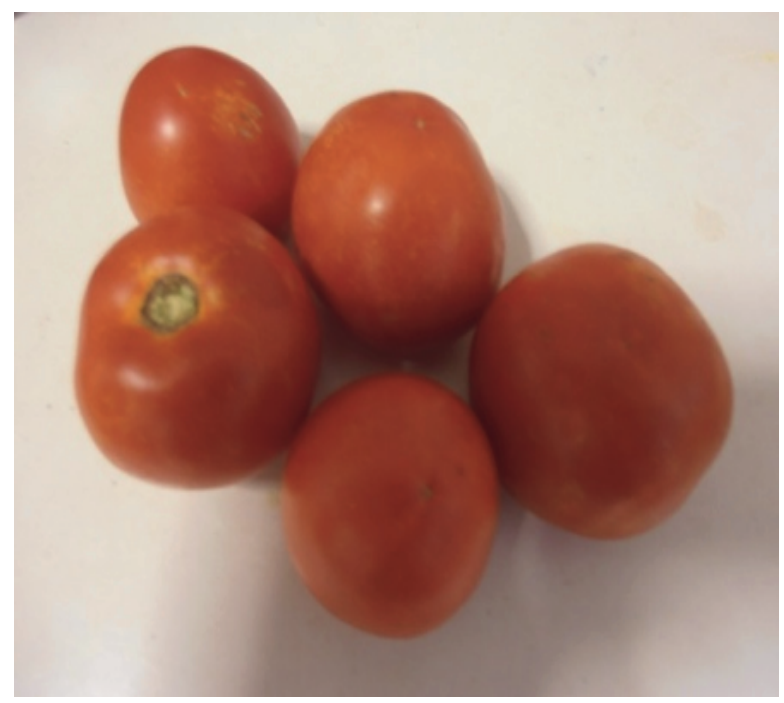

Figure 1. Tomatoes in F3, to $90 \%$ red pigmentation

The level of losses recorded has been determined by weighing before and after storage.

The soluble dry substance has been determined using the ABBE refractometer, Prisma model. The sugar amount has been determined by the Bertrand method. The vitamin $C$ has been determined after storage using the spectrophotometric method with the measurement of 
the chloroform color intensity (extraction of ascorbic acid with oxalic acid solution, treatment with indophenol dye extracted into chloroform), with the results in $\mathrm{mg} / 100 \mathrm{~g}$ of the product (Sora et al., 2019).

Total acidity has been determined by the volumetric method with the result expressed in $\mathrm{g}$ malic acid/100 g of the product.

The determination of aspect, texture and taste changes were made by some qualifying ('very good' or 'good'), as follows:

- $\quad$ aspect $(15 \%)$,

- texture $(35 \%)$,

- taste $(50 \%)$.

It was used a scale from $0-100$ points:

- very good (80-100),

- $\operatorname{good}(60-79)$,

- acceptable (40-59),

- mediocre (20-39),

- inappropriate (0-19), recommended by Niculescu et al. (2010); Sora et al., (2019).

Determination of firmness of the fruit has been made by the penetration in 4 distinct points with the penetrometer, 2 and 0,1 penetrometer unit (PU).

Statistical interpretation has been performed with Duncan's test (Săulescu and Săulescu, 1967).

\section{RESULTS AND DISCUSSIONS}

The results obtained regarding the level of registered losses, the evolution of some chemical components, as well as the organoleptic evaluation of the tomatoes kept under the researched conditions, are presented in tables 2, 3, 4 and the appearance and the firmness of the tomatoes are shown in the figures $2,3,4$.

Table 2. Losses during storage of tomatoes

\begin{tabular}{|c|r|r|r|c|}
\hline \multirow{2}{*}{ Variant } & \multicolumn{3}{|c|}{ Losses (\%) } & Storage duration (days) \\
\cline { 2 - 4 } & mass & by spoilage & total & \\
\hline V1 & 32.0 & 20.1 & $52.1 \boldsymbol{a}$ & 20 \\
\hline V2 & 1.5 & - & $1.5 \boldsymbol{d}$ & -idem- \\
\hline V3 & 20.0 & 3.3 & $23.3 \boldsymbol{c}$ & -idem- \\
\hline V4 & 0.3 & - & $0.3 \boldsymbol{e}$ & -idem- \\
\hline V5 & 22.0 & 9.5 & $32.5 \boldsymbol{b}$ & -idem- \\
\hline V6 & 1.2 & - & $1.2 \boldsymbol{d}$ & -idem- \\
\hline
\end{tabular}

(values followed by same letter do not differ significantly from 5\% significance level, Duncan test)

There are important differences in the mass loss and spoilage of tomatoes during storage; under conditions of hemibiosis, V1 (control) has had the highest losses (52.1\%) compared to V5 (32.5\%) and V3 (23.3\%) and under conditions of physioanabiosis, V2 (control) has had the highest losses (1.5\%) compared to V6 (1.2\%) and V4 (0.3\%).

Losses by damage during storage of tomatoes in hemibiosis conditions have been recorded due to the appearance of pathogenic fungi Alternaria porii f. solani and Colletotrichum coccodes that caused alternariosis and anthracnose (Figure 2).

The difference has been significant between the tomatoes of grafted plants and the tomatoes of non-grafted plants; the best results are in tomatoes grafted on the 'Emperador' rootstocks (V3-hemibiosis and V4-physioanabiosis) and the tomatoes under conditions of physioanabiosis have had the lower losses compared to the conditions of hemibiosis. 


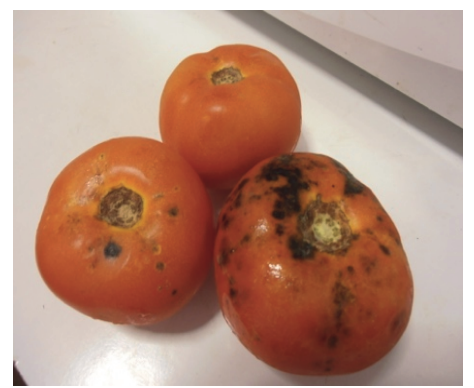

V1

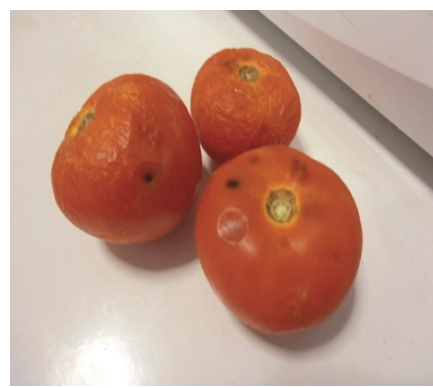

V3

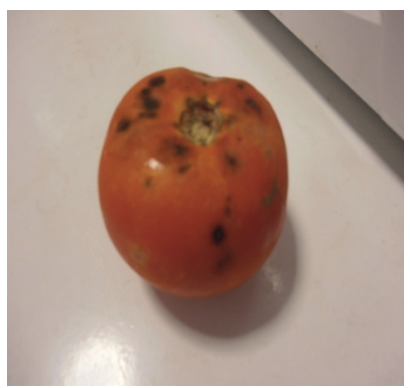

V5

Figure 2. Aspects of storing tomatoes in hemibiosis conditions

The composition of some biochemical components of tomatoes during storage is shown in table 3 .

Table 3. Evolution of some biochemical components of tomatoes during storage

\begin{tabular}{|c|c|c|c|c|}
\hline Variant & \multicolumn{4}{|c|}{ Biochemical determinations } \\
\cline { 2 - 5 } & $\begin{array}{c}\text { Dry substance } \\
\left({ }^{\circ} \text { Brix } / 20^{\circ} \mathrm{C}\right)\end{array}$ & $\begin{array}{c}\text { Sugar } \\
(\%)\end{array}$ & $\begin{array}{c}\text { Acidity } \\
\text { (g malic acid/100g) }\end{array}$ & $\begin{array}{c}\text { Vitamin C } \\
(\mathrm{mg} / 100 \mathrm{~g})\end{array}$ \\
\hline V1 & $4.1 \boldsymbol{b}$ & $0.51 \boldsymbol{a}$ & $3.05 \boldsymbol{a}$ & $39.95 \boldsymbol{a}$ \\
\hline V2 & $4.0 \boldsymbol{b}$ & $0.50 \boldsymbol{a}$ & $3.02 \boldsymbol{a}$ & $39.94 \boldsymbol{a}$ \\
\hline V3 & $3.6 \boldsymbol{c}$ & $0.32 \boldsymbol{b}$ & $2.05 \boldsymbol{c}$ & $38.39 \boldsymbol{b}$ \\
\hline V4 & $3.9 \boldsymbol{c}$ & $0.30 \boldsymbol{b}$ & $2.00 \boldsymbol{c}$ & $38.37 \boldsymbol{b}$ \\
\hline V5 & $5.3 \boldsymbol{a}$ & $0.52 \boldsymbol{a}$ & $2.79 \boldsymbol{b}$ & $36.47 \boldsymbol{c}$ \\
\hline V6 & $5.2 \boldsymbol{a}$ & $0.50 \boldsymbol{a}$ & $2.75 \boldsymbol{b}$ & $36.48 \boldsymbol{c}$ \\
\hline
\end{tabular}

(values followed by same letter do not differ significantly from $5 \%$ significance level, Duncan test)

The content of tomatoes in the dry substance, total sugar, acidity and vitamin $\mathrm{C}$ have varied depending on the variant.

The control variants (V1 and V2) have had slightly higher values of biochemical composition compared to variants V3 and V4 and have had lower values of dry substance and higher values of acidity and vitamin C content compared to V5 and V6 in which the dry substance has had the highest values and vitamin $C$ has had the lowest values.

At the content of tomatoes in the sugar, the best results are in the tomatoes grafted on the 'Buzău' rootstocks (V5, V6) and in non-grafted tomatoes (V1, V2) compared to the tomatoes grafted on the 'Emperador' rootstock; the difference has been significant between the variants.

The rootstock has influenced the biochemical composition of the tomatoes during storage under research conditions.

The results regarding tomato firmness are shown in figures 3 and 4 . 


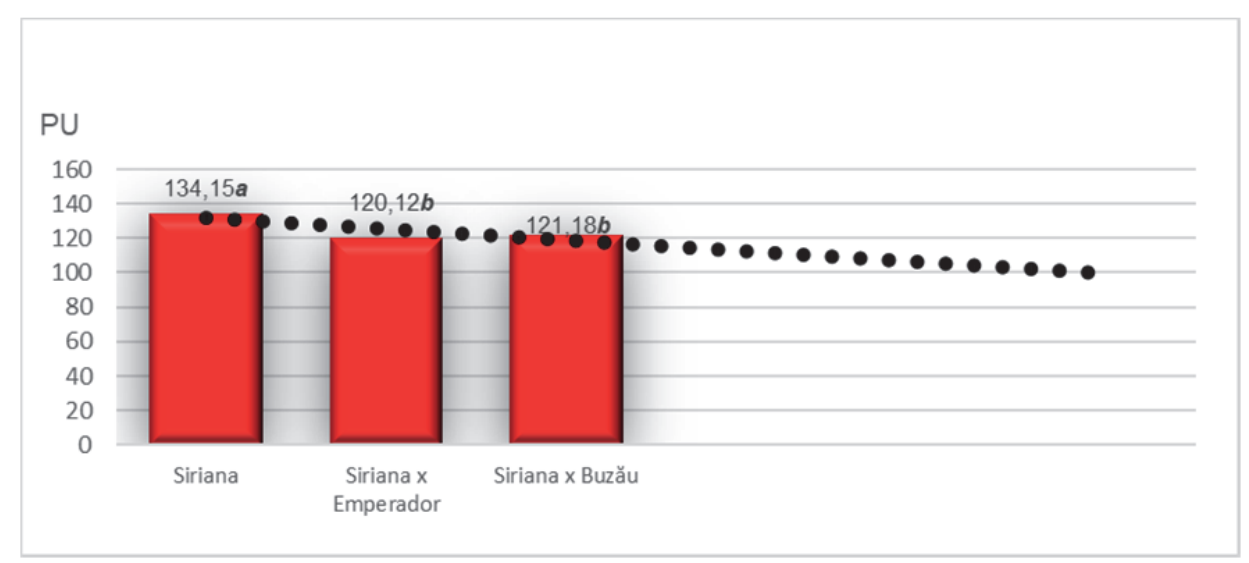

(values followed by same letter do not differ significantly from 5\% significance level), Duncan test

Figure 3. Firmness of tomatoes in fresh condition, initial (penetrometric units)

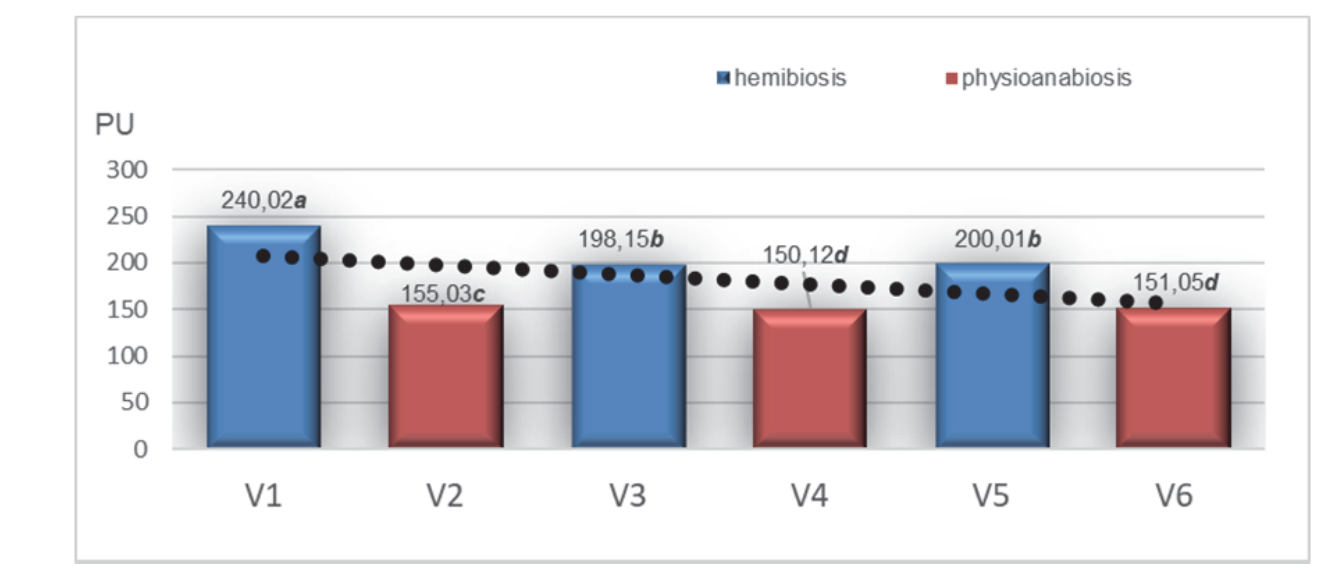

(values followed by same letter do not differ significantly from 5\% significance level), Duncan test

Figure 4. Evolution of tomato firmness during storage (penetrometric units)

Grafting, respectively rootstock, has influenced positively the firmness of the fruit; the fresh fruits from the grafted plants have been firmer (120.12 PU at the fruits from the plants grafted on 'Emperador' and 121.18 PU the fruits from the plants grafted on 'Buzău' compared to 134.15 PU from the fruits from non-grafted plants). The difference has been significant between grafted plants and non-grafted plants and insignificant between the two non-grafted plant variants.

In both storage conditions, there is a better firmness of the V3, V5, V4 and V6 variants compared to the control variants, $\mathrm{V} 1$ and $\mathrm{V} 2$.

Under hemibiosis conditions, the firmness of the variants varied between 198.15 PU to $240.02 \mathrm{PU}$; the grafted variants V3 and V5 had better firmness compared to the control variant V1, the difference has been significant. And in conditions of physioanabiosis, the firmness of the variants varied between 150.12 PU to 155.03 PU; variants V2 and V4 have had better firmness compared to control variant V2, the difference has been insignificant. The rootstock does not influence the firmness during the storage period under the research conditions, the differential evolution between the initial phase and after storage is similar to the grafted and non-grafted variants. 
The results of the organoleptic determinations on the appearance, textures and taste of the fruit from the grafted and non-grafted tomato variants, fresh and after storage under the research conditions are given in Table 4.

Table 4. Organoleptic determinations in tomatoes

\begin{tabular}{|c|r|r|r|r|c|}
\hline \multirow{2}{*}{ Variant } & \multicolumn{4}{|c|}{ Organoleptic assessment (score) } & \multirow{2}{*}{ Qualifying } \\
\cline { 2 - 5 } & appearance & texture & taste & \multicolumn{1}{c|}{ total } & \\
\hline initial & 14.90 & 34.90 & 50.00 & 99.80 & very good \\
\hline V1 & 12.93 & 24.85 & 45.22 & 83.00 & very good \\
\hline V2 & 13.85 & 30.92 & 47.30 & 92.07 & very good \\
\hline initial & 15.00 & 35.00 & 50.00 & 100.00 & very good \\
\hline V3 & 13.82 & 30.23 & 45.34 & 89.39 & very good \\
\hline V4 & 14.90 & 33.00 & 47.52 & 95.42 & very good \\
\hline initial & 12.00 & 34.50 & 32.40 & 78.90 & good \\
\hline V5 & 10.75 & 34.05 & 34.20 & 79.00 & good \\
\hline V6 & 11.88 & 30.85 & 35.23 & 77.96 & good \\
\hline
\end{tabular}

In terms of quality aspects, texture and taste, the tomato variants grafted on 'Emperador' rootstock have obtained the 'very good' grade, the tomato variants grafted on the 'Buzău' rootstock have obtained the 'good' grade, compared to non-grafted tomato variants (control), which have obtained the 'very good' rating.

Grafting, respectively rootstock has influenced the quality of fresh tomatoes, respectively the 'Emperador' rootstock has influenced positively and the 'Buzău' rootstock has influenced negatively the researched organoleptic aspects, but does not influence these aspects during storage under experienced stat

\section{CONCLUSIONS}

The rootstock has influenced the total losses recorded on tomatoes during the storage: the highest mass and spoilage losses of the tomatoes has been recorded in non-grafted tomatoes (52.1\% in hemibiosis, $1.5 \%$ in physioanabiosis), then in tomatoes grafted on the 'Buzău' rootstock (23.3\% in hemibiosis, $0.3 \%$ in physioanabiosis) and on the 'Emperador' rootstock (32.5\% in hemibiosis, $1.2 \%$ in physioanabiosis).

Regarding the composition in the biochemical components investigated, the rootstocks used have influenced the quality of the fruit during the storage.

The rootstock not influence the firmness during the storage of the fruits for a duration of approx. 3 weeks in research storage states.

The rootstock has influenced the quality of fresh tomatoes, respectively the 'Emperador' rootstock has influenced positively ('very good' rating; 89.39-95.42 score) and the 'Buzău' rootstock has influenced negatively ('good' rating; 77.96-79 score) the researched organoleptic aspects.

The obtained results require the extension of the researches and on other grafted solanaceous and cucurbitaceous vegetable species, as well as on other storage states.

\section{ACKNOWLEDGEMENTS}

This research is part of 2017-2019 intern research program of the Horting Institute ('Influence of rootstock on the behavior at storage in different states of grafted Romanian 
vegetable production obtained from the crops established in the greenhouse or field') which is supported by The Academy of Agricultural and Forestry Sciences 'Gheorghe IonescuȘișești' Bucharest.

\section{REFERENCES}

1. Beceanu D., Chira A. (2003). Tehnologia produselor horticole: valorificare în stare proaspătă și industrializare. (Horticultural product technology: valorization in fresh condition and processing). Editura Economică, București.

2. Chaux C., Foury C. (1994). Production légumirès. Tome 3, Technique et Documentation - Lavoisier. Coll. Agriculture d'aujourd'hui.

3. Niculescu F., Romas M., Temocico G., Niculescu A. (2010). Comportarea la păstrare în diferite condiții a prunelor. (Behavior in storage under different conditions of plums). Lucrări Ştiinţifice ICDIMPH Horting București, XXVII.

4. Săulescu N.A., Săulescu N.N. (1967). Cîmpul de experienţă. (Field of experience). Editura Agro-Silvică, Bucureşti.

5. Sora D., Doltu M., Drăghici E.M., Bogoescu M. (2019). Effect of grafting on tomato fruit qulity. Notulae Botanicae Horti Agrobotanici Cluj-Napoca, 47(4): 1246-125 